\title{
CB13, a novel PPARy ligand, overcomes radio-resistance via ROS generation and ER stress in human non-small cell lung cancer
}

\author{
Tae Woo Kim', Da-Won Hong ${ }^{1}$ and Sung Hee Hong ${ }^{1}$
}

\begin{abstract}
Peroxisome proliferator-activated receptor gamma (PPARY) is a well-known therapeutic target for type 2 diabetes as well as is a potential target for effective anti-cancer drug, since PPARy ligands such as ciglitazone (Cig) frequently cause cell death in many types of cancer cells and suppress tumor growth. However, many cancer patients acquire chemoresistance or radio-resistance after chemo or radiotherapy, and it is still unclear. In the difficulty of well-known anticancer drugs, we developed a novel PPARY agonist CB13 (1-benzyl-5-(4-methylphenyl) pyrido [2,3-d]pyrimidine-2,4 $(1 \mathrm{H}, 3 \mathrm{H})$-dione) and investigated the anti-cancer effect and cell death mechanism on human non-small cell lung cancer (NSCLC) cells. With anti-cancer effect of Cig, CB13 also causes inhibition of cell growth by decreasing cell viability, increasing the release of $\mathrm{LDH}$, and increasing caspase-3, and caspase-9 activities. CB13 generates reactive oxygen species (ROS) and causes cell death via ER stress in NSCLC and radio-resistant NSCLC cells (A549R and H460R), and a combination of CB13 and radiation induces greater ER stress and cell death when compared to CB13 alone. Taken together, our results suggest that a combination of CB13 and radiation may overcome radio-resistance caused by radiotherapy.
\end{abstract}

\section{Introduction}

Lung cancer is a leading cause of cancer-related deaths and the most common cancer worldwide according to 2018 cancer statistics ${ }^{1}$. Lung cancers are classified into two types: small-cell lung cancer (SCLC) and non-smallcell lung cancer (NSCLC). SCLC is responsible for $\sim 10-15 \%$ of all lung cancer cases, and NSCLC is responsible for the other $80-85 \%^{2}$. NSCLC is comprised of more epithelial lung cancer types than SCLC, and it frequently becomes resistant to chemotherapy ${ }^{3}$. Radio therapy is an effective therapeutic strategy against lung cancer, but it frequently causes radio-resistance ${ }^{4}$. Therefore, understanding the mechanism that cause radioresistance is important for maintaining radiotherapy efficacy. Radio-resistance is caused by clonogenic cells within

Correspondence: Sung Hee Hong (gobrian@kcch.re.kr)

'Division of Radiation Biomedical Research, Korea Institute of Radiological and Medical Sciences, Seoul 139-706, Korea

Edited by A. Finazzi-Agrò the tumor and by acquired cancer radio-resistance ${ }^{5,6}$. Radiation often causes an EMT phenotype, and cancer cells that gain an EMT phenotype present a large obstacle for effective radiotherapy ${ }^{7}$. Therefore, when developing novel and effective drugs for the treatment of lung cancer, it is important to focus on overcoming radio-resistance. Peroxisome proliferator-activated receptors (PPARs) are type II nuclear hormone receptors for thyroid hormone, retinoic acid, and steroid ${ }^{8}$. PPARs form heterodimers with retinoic X receptor (RXR) and become activated by specifically binding to PPAR response elements (PPREs) ${ }^{9,10}$. There are three types of PPARs: $\alpha, \beta$, and $\gamma$. Each is encoded by a separate gene and displays a distinct pattern of tissue distribution ${ }^{11,12}$. PPARy has anti-inflammatory properties and plays a central role in the differentiation of adipocyte cells, tumor suppression, and metabolism ${ }^{13,14}$. PPARy is up-regulated in many cancer cell types, but the effect of numerous PPARy ligands, including 15-deoxy$\Delta 12,14-$ prostaglandin $\mathrm{J} 2$ and thiazolidinediones (TZDs),

\section{(c) The Author(s) 2020}

(c) Open Access This article is licensed under a Creative Commons Attribution 4.0 International License, which permits use, sharing, adaptation, distribution and reproduction cc) in any medium or format, as long as you give appropriate credit to the original author(s) and the source, provide a link to the Creative Commons license, and indicate if changes were made. The images or other third party material in this article are included in the article's Creative Commons license, unless indicated otherwise in a credit line to the material. If material is not included in the article's Creative Commons license and your intended use is not permitted by statutory regulation or exceeds the permitted use, you will need to obtain permission directly from the copyright holder. To view a copy of this license, visit http://creativecommons.org/licenses/by/4.0/. 
inhibit tumor growth in several cancer types (e.g. lung, ovarian, pancreatic, and colon) and cause cell death ${ }^{15-}$ 20 . Thus, these receptors are an attractive target and have made a significant impact on novel synthetic anticancer agent development. An increasing number of studies have demonstrated that TZD, a synthetic class of PPARy ligand that includes ciglitazone (Cig), rosiglitazone, pioglitazone, and troglitazone, prevents cancer cell growth $^{21,22}$. Recent reports have shown that PPARy receptors and their ligands can suppress tumor growth by mediating cell cycle arrest and apoptosis in colon cancer $^{23}$. One recent study suggested that PPARy ligands cause cell death in various cancers and regulate diverse cancer pathways ${ }^{24}$.

The endoplasmic reticulum (ER) participates in various functions, including protein folding, post-translational modification, secretory protein synthesis, and cellular calcium storage. In addition to these functions, the unfolded protein response (UPR) is a cellular stress response that causes cellular damage and apoptosis ${ }^{25}$. UPR is mediated by three membrane transducers: pancreatic ER kinase-like endoplasmic reticulum kinase (PERK), activating transcription factor (ATF6), and inositol requiring enzyme 1 (IRE1) ${ }^{26}$. UPR is a cellular protective response against ER stress conditions, but an accumulation of UPR initiates pro-apoptotic signaling that includes the activation of CHOP (also known as GADD153) ${ }^{27}$. Many studies have shown that TZDs can up-regulate ER stress markers and cause cell death in breast cancer cells. In breast cancer cells, $\Delta 2$-troglitazone triggers cell death via ER stress ${ }^{28}$. Both Cig and troglitazone activate the PERK-elF2 $\alpha$ pathway in rat liver epithelial cells ${ }^{29}$. Cig, a known PPARy ligand, induces ER stress-mediated cell death via the PERK axis in NSCLC cells and contributes to caspase-3, -4, -8, -9, and -12 cleavage $^{30}$. Mounting evidence indicates that ROS production leads to ER stress-induced cell death, and ER stress is also regulated by ROS inhibitors, which indicates ROS is a regulator of ER stress ${ }^{31}$. An increasing number of reports have shown that exosomes, nanoscale vesicles $(50-150 \mathrm{~nm}$ in diameter), participate in cell-cell communication and confer ER stress signals ${ }^{32}$. Particularly, we found a relationship between PPARy ligands and exosomes in NSCLC cells. These novel finding elaborates on the anti-cancer mechanism that allow CB13 treatment to overcome radio-resistance.

In this study, we evaluated the anti-cancer effect of CB13 (a novel PPARY agonist candidate) and investigated the role of PPARy, ROS, exosomes, and ER stress in CB13-induced cell death in human NSCLC and radio-resistant NSCLC cells. Moreover, we demonstrated that $\mathrm{CB} 13$ and radiation co-treatment can overcome radio-resistance via ER stress in radioresistant NSCLC cells.

\section{Results}

Identification of CB13 as a novel PPARy ligand in 3T3-L1 cells

In an effort to identify novel anti-cancer agents, we obtained (1-benzyl-5-(4-methylphenyl) pyrido [2,3-d] pyrimidine-2,4(1H,3H)-dione) ( $\mathrm{CB} 13)$ from ChemBridge. Figure 1a shows the chemical structures of $\mathrm{CB} 13$ and Cig. PPARy ligands, including $\mathrm{Cig}$ and rosiglitazone, frequently induce adipocyte differentiation and play a key role in regulating adipogenesis ${ }^{33}$. To confirm CB13's capacity as a PPARy ligand, we measured PPRE-luciferase activity in 3T3-L1 cells exposed to CB13 and Cig. Both CB13 and Cig increased luciferase activity in 3T3-L1 cells (Fig. 1b). We determined whether CB13, as a PPARy ligand candidate, could differentiate adipocytes in 3T3-L1 cells using Cig as a positive control. As shown in Fig. 1c and d, Oil Red O staining confirms that CB13 and Cig cause adipocyte differentiation in 3T3-L1 cells, and GW9662, a PPAR- $\gamma$ antagonist, blocks CB13-induced adipocyte differentiation. Western blot analysis revealed that CB13 and Cig mediated increased PPARy expression, but GW9662 suppressed CB13-induced PPARy expression (Fig. 1e).

\section{CB13 induces cell death in NSCLC cells}

To investigate the cytotoxic effect of CB13, WST-1, and LDH assays were performed and caspase- 3 and -9 activities were used to monitor the survival of A549 and H460 cells after treatment with CB13 or Cig. CB13 and Cig reduced cell viability, increased LDH release, and increased caspase- 3 and -9 activities (Fig. 2a-d). An annexin V FACs assay showed an increase in apoptosis signaling in CB13- and Cig-treated A549 and H460 cells (Fig. 2e). To examine the molecular mechanisms of CB13mediated cell death, Western blot analyses were performed. They indicate that CB13 and Cig increased PARP cleavage, caspase- 3 levels, and caspase- 9 levels in A549 and $\mathrm{H} 460$ cells (Fig. 2f). These results demonstrate that CB13 mediates anti-cytotoxic effects by inducing apoptosis in NSCLC cells. In a pharmacological experiment using the caspase inhibitor, Z-VAD-FMK, we co-treated A549 and H460 cells with Z-VAD-FMK and CB13. This combination prevented CB13 from decreasing cell viability and increasing LDH release as well as caspase- 3 and -9 cleavage (Fig. $2 \mathrm{~g}-\mathrm{i}$ ).

\section{CB13 induces cell death via ER stress in NSCLC cells}

To further determine the mechanism through which CB13 regulates cell death, we treated A549 and H460 cells with $\mathrm{CB} 13$ in a time-dependent manner and performed WST-1, LDH, and caspase- 3 and -9 activity assays. The results indicate that $\mathrm{CB} 13$ reduced cell viability, increased LDH cytotoxicity, and increased caspase- 3 and -9 activities in a time-dependent manner (Fig. $3 a-c)$. A recent 


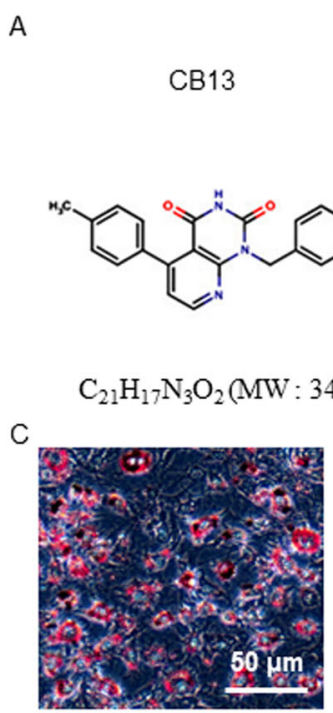

DMSO

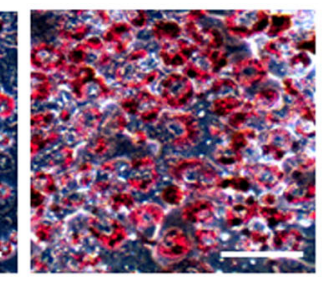

Cig

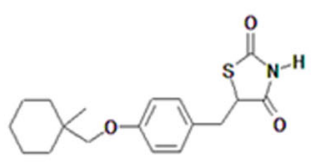

$\mathrm{C}_{18} \mathrm{H}_{23} \mathrm{NO}_{3} \mathrm{~S}(\mathrm{MW}: 333.5)$
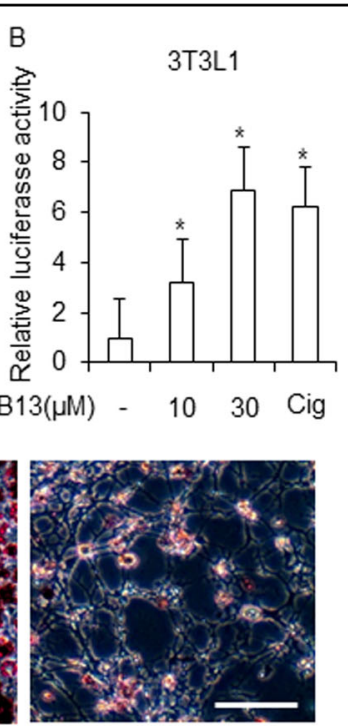

CB13 + GW9662

CB13

E

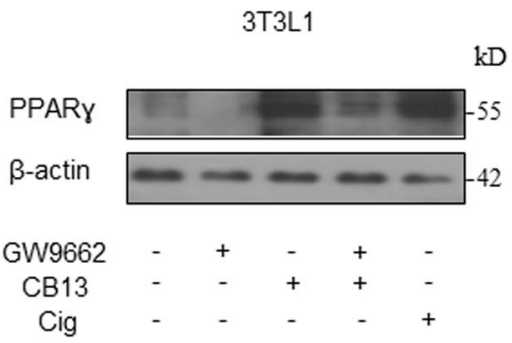

Fig. 1 Adipocyte differentiation in CB13-treated 3T3-L1 cells. a The chemical structures and molecular formulas of CB13 and Cig. b 3T3-L1 cells were transiently transfected with $2 \mu \mathrm{g}$ of the PPAR response element reporter gene (pGL3-PPRE vector) and the PGL3-PPRE vector and treated with

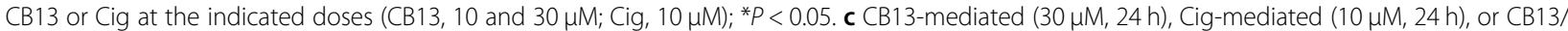
GW9662-mediated adipocyte differentiation was assessed by the presence of Oil Red O-stained droplets. Oil Red O-stained cells were detected using a light microscope and scoring cells from each dish at $\times 400$ magnification. $\mathbf{d}$ Oil Red $\mathrm{O}$ quantification was performed by adding a dye extraction solution to each well and measuring the absorbance at $510 \mathrm{~nm}$. Values indicate the means \pm SE of three replicates $\left({ }^{*} P<0.05\right.$, ${ }^{* *} P<0.01$ vs. control; Student's t-test). e Effect of GW9662 on CB13-treated 3T3-L1 cells. 3T3-L1 cells were pretreated with GW9662 (20 $\mu$ M) for $4 \mathrm{~h}$ and then treated with CB13 $(30 \mu \mathrm{M})$. 3T3-L1 cells were also treated with Cig $(10 \mu \mathrm{M})$ as a control. Total lysates were interrogated by Western blot analysis to confirm inhibition of PPARy. $\beta$-actin was used as a protein loading control.

report suggested that ER stress plays an important role in cell death, and CHOP is a major component of the ER stress-mediated apoptosis pathway ${ }^{34}$. To investigate whether CB13 causes ER stress-mediated cell death, we treated A549 and H460 cells with CB13 in a timedependent manner and measured various ER stress signals using Western blot analysis. From the cell lysates generated in this experiment, we observed increased GRP78, p-PERK, p-eIF2 $\alpha$, ATF4, and CHOP expression (Fig. 3d). Interestingly, in this condition, we isolated exosomes from the supernatants and quantified them using Ponceau $\mathrm{S}$ staining and immunoblotting with a CD63-specific antibody (Fig. 3d). The Western blot analysis suggests that exosomes mediate time-dependent ER stress-induced cell death in cells treated with CB13, which indicates the induction of GRP78 and CHOP (Fig. 3d). These results suggest that ER stress confers cell death via PERK-eIF2 $\alpha$-ATF4-CHOP signaling in CB13-treated cells. Pharmacological studies revealed a decrease in cell viability and an increase in LDH cytotoxicity after treatment with thapsigargin (TG, an ER stress inducer) or CB13, which indicates cell death. Furthermore, A549 and H460 cells treated with a combination of TG and CB13 had lower cell viability and a greater increase in LDH release than A549 and $\mathrm{H} 460$ cells treated with $\mathrm{CB} 13$ or TG, alone (Fig. 3e, f). Under these conditions, Western blot analysis indicated that cells co-treated with TG/ CB13 showed higher levels of GRP78, p-PERK, p-eIF2 $\alpha$, 


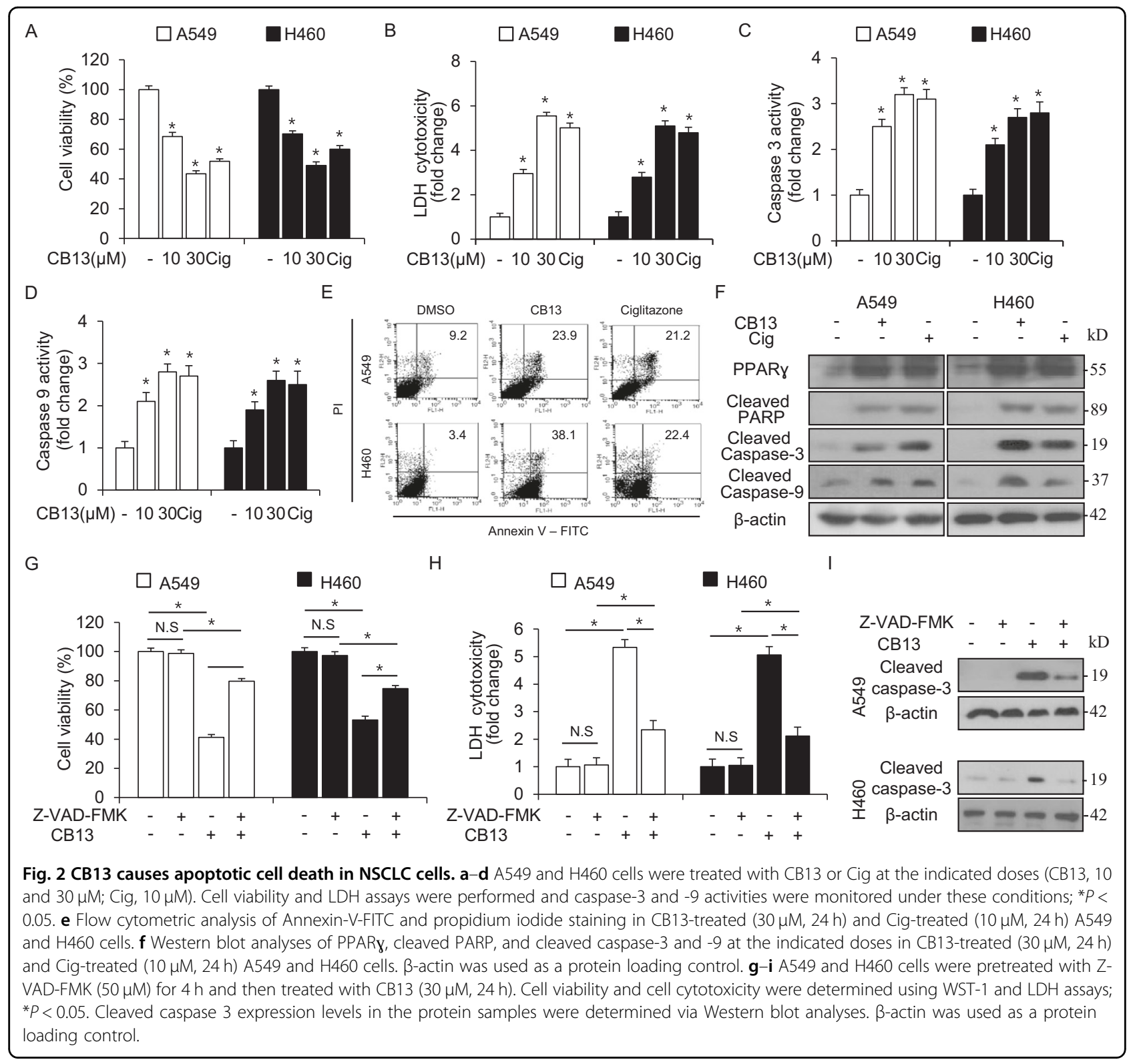

ATF4, and CHOP expression and higher levels of caspase3 cleavage than cells treated with $\mathrm{CB} 13$ or TG, alone (Fig. 3g).

\section{Inhibition of ER stress suppresses CB13-induced cell death in NSCLC cells}

To further investigate whether CB13 regulates cell death through ER stress in NSCLC cells, we treated A549 and $\mathrm{H} 460$ cells with CB13 after knocking down PERK and CHOP with specific siRNAs. CB13 did not decrease cell viability, and it did not increase LDH release in PERK or CHOP knockdowns when compared to control (CTL) cells (Fig. 4a, b, d, e). Western blot analysis suggested that CB13 suppresses PERK and eIF2 $\alpha$ phosphorylation, caspase-3 cleavage, and ATF4 and CHOP expression in PERK knockdown cells when compared to CTL cells (Fig. 4c). Moreover, when exosome samples were stained with Ponceau $\mathrm{S}$ and quantified, they indicated that $\mathrm{CB} 13$ inhibits CHOP and CD63 expression in PERK knockdown cells when compared to CTL cells (Fig. 4c). Western blot analysis revealed that $\mathrm{CB} 13$ blocks $\mathrm{CHOP}$ expression and caspase-3 and -9 cleavage in CHOP knockdown cells when compared to CTL cells (Fig. 4f).

\section{CB13 induces ER stress and cell death via ROS generation in NSCLC cells}

An increasing number of studies suggest that ER stress and the generation of reactive oxygen species (ROS) are 


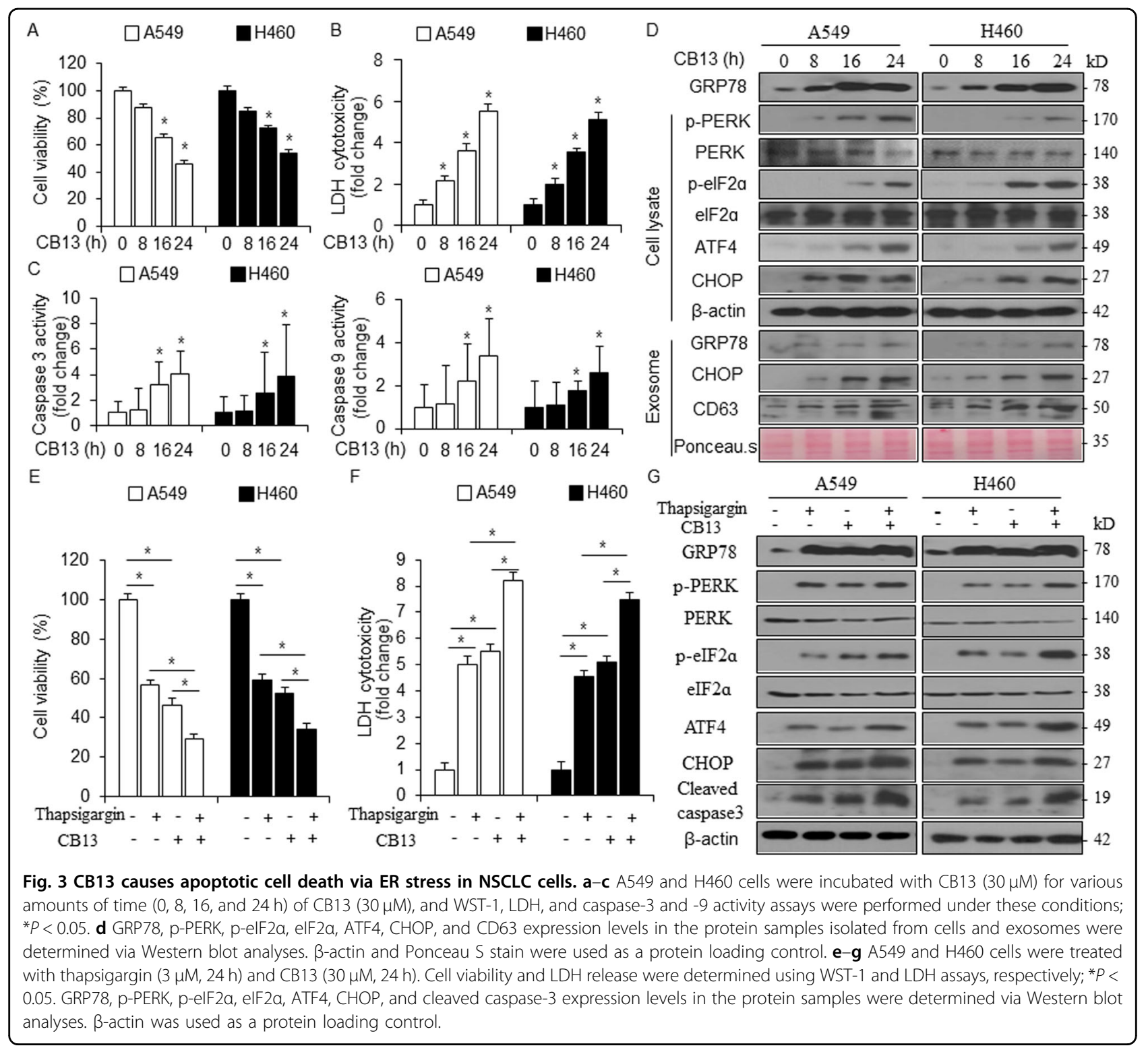

closely related, and the related pathway may regulate cell death $^{35}$. Elevated ROS production induces cell death via ER stress in cancer cells, and ROS scavengers (e.g. NAC) regulate ER stress and cell death through ROS generation, indicating ROS drives ER stress ${ }^{36}$. To further investigate whether CB13 mediates ROS generation, we examined intracellular ROS with flow cytometry after labeling with the fluorescent probe DCFDA. After an $8 \mathrm{~h}$ incubation with CB13, DCFDA fluorescence increased by 1.5-2-fold in A549 and H460 cells when compared to DMSO-treated cells (Fig. 5a). To probe the sources of CB13-mediated ROS production in A549 and H460 cells, several ROS inhibitors such as Apo and DPI were used in combination with CB13. As shown in Fig. 5b, c, DPI dramatically inhibited CB13's ability to reduce cell viability and increase LDH cytotoxicity, but not Apo. Western blot analysis revealed that DPI inhibits $\mathrm{CB} 13$ from increasing the expression of GRP78, p-PERK, p-eIF2 $\alpha$, ATF4, CHOP, and caspase-3 cleavage in A549 and $\mathrm{H} 460$ cells, but not Apo (Fig. 5d).

\section{PPARy inhibition suppresses CB13-mediated cell death in NSCLC cells}

PPARY ligands, including 1-(trans-methylimino-Noxy)-6-(2-morpholinoethoxy)-3-phenyl-(1H-indene-2-

carboxylic acid ethyl ester) (KR-62980) and rosiglitazone, exert anti-lung cancer effects by inducing ROS production, apoptosis, and differentiation and by inhibiting cell viability $^{37}$. To further test whether CB13 mediates cell death via PPARy activation, we performed knockdown 


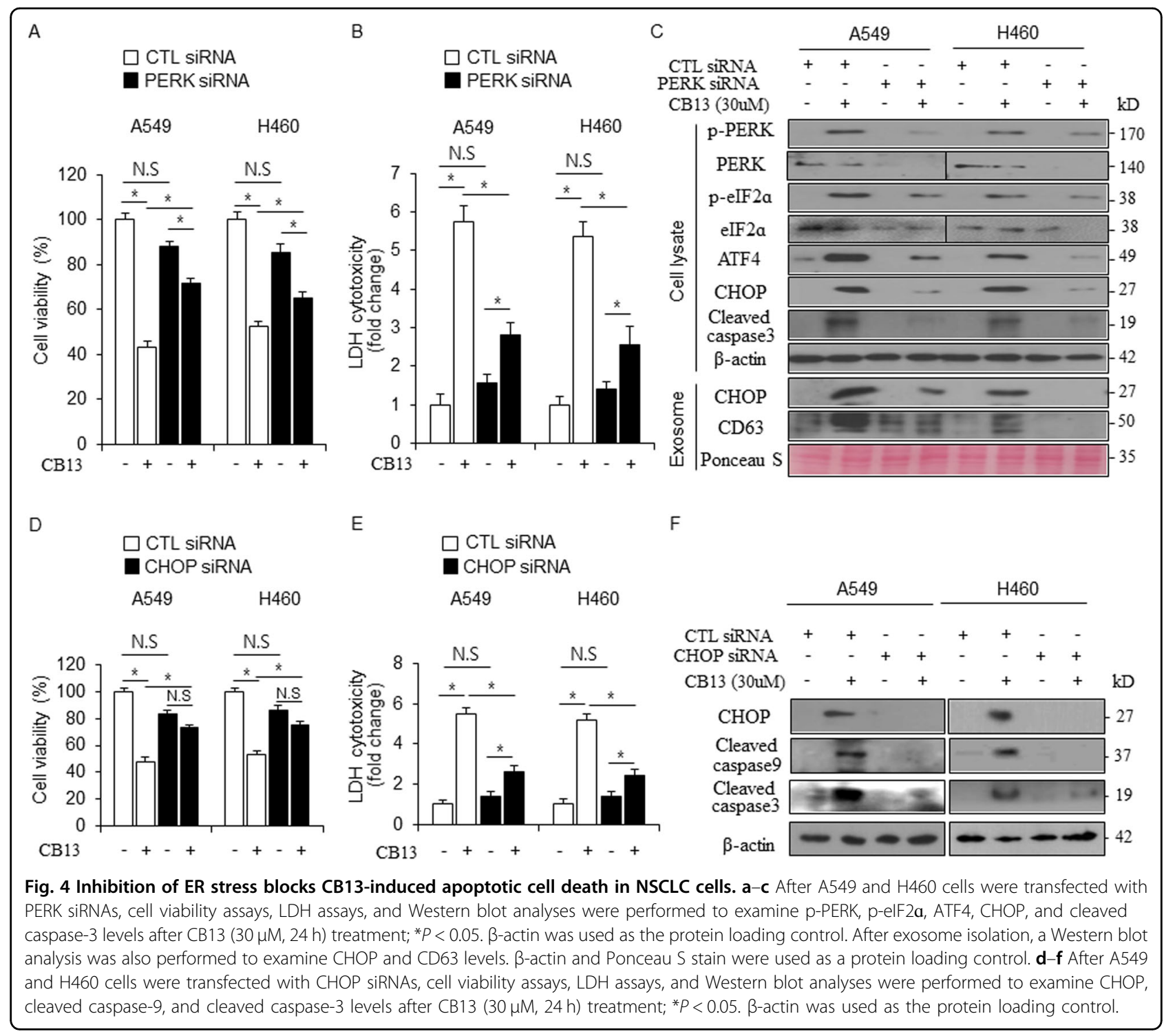

experiments using PPARy-specific siRNAs in A549 and H460 cells, cell viability and LDH assays, and Western blot analyses. The results show that CB13 did not decrease cell viability, and it did not increase LDH cytotoxicity in PPARy knockdown cells when compared to CTL cells (Fig. 6a, b). After quantifying PPARy knockdown in A549 and H460 cells, Western blot analysis indicated that CB13 induces PPARy, p-PERK, p-eIF2 $\alpha$, and $\mathrm{CHOP}$ expression and cleavage of caspase- 3 in cells transfected with CTL siRNAs. Conversely, CB13 inhibits the expression of these proteins in PPARy knockdown cells (Fig. 6c). To further investigate whether PPARy activation regulates CB13-mediated cell death in NSCLC cells, we transfected $\mathrm{H} 460$ cells with PPARy-specific shRNAs. Positive cells were selected with puromycin and established into stable PPARy knockdown cells. We treated PPARy knockdown stable H460 cells with CB13,
GW9662, or CB13/GW9662, and performed cell viability and LDH assays as well as Western blot analyses. In CTL cells, GW9662 had no effect, CB13 decreased cell viability and increased LDH cytotoxicity, and GW9662/CB13 inhibited CB13's ability to reduce cell viability and increase LDH release when compared to CB13 treatment, alone. However, in PPARy shRNA stable H460 cells, CB13, GW9662, and GW9662/CB13 had no effect on cell viability or LDH release (Fig. 6d, e). In CTL cells, Western blot analyses suggested that $\mathrm{CB} 13$ induces the expression of PPARy, p-PERK, p-eIF2 $\alpha$, ATF4, and CHOP and cleavage of caspase-3, but GW9662 and GW9662/CB13 blocks the expression of PPARy, p-PERK, p-eIF2 $\alpha$, ATF4, and $\mathrm{CHOP}$ and cleavage of caspase-3 (Fig. 6f). In PPARy shRNA stable H460 cells, CB13, GW9662, and GW9662/ CB13 did not affect the expression of the above markers (Fig. 6f). 

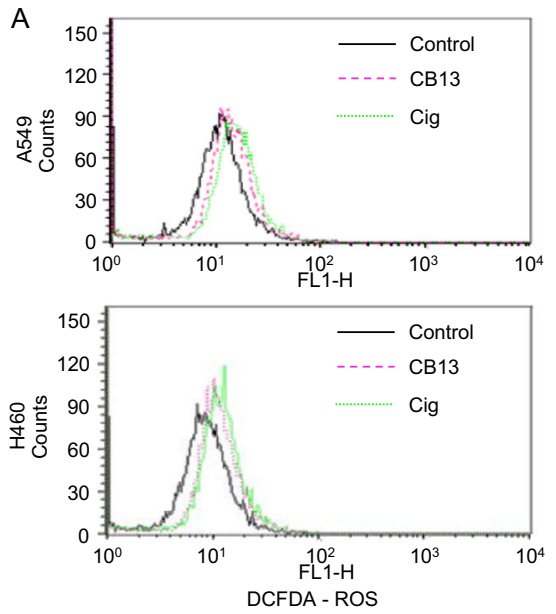

C

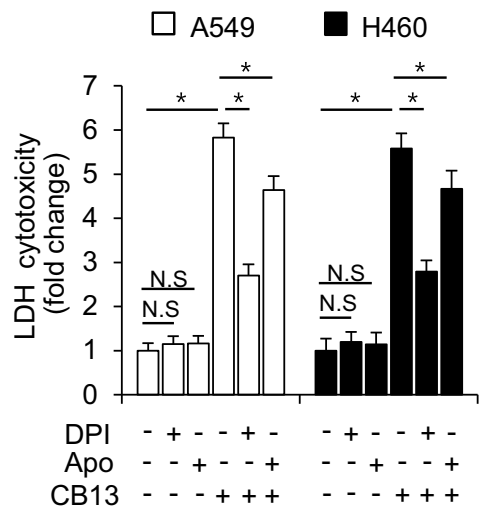

B

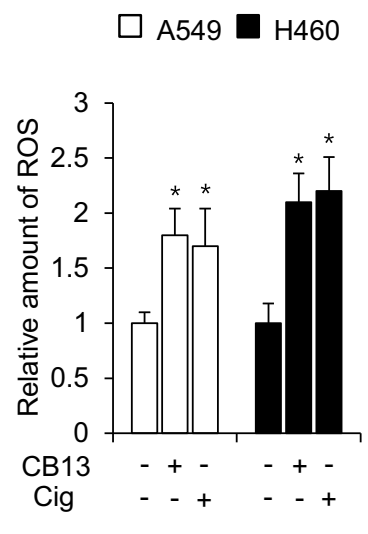

D

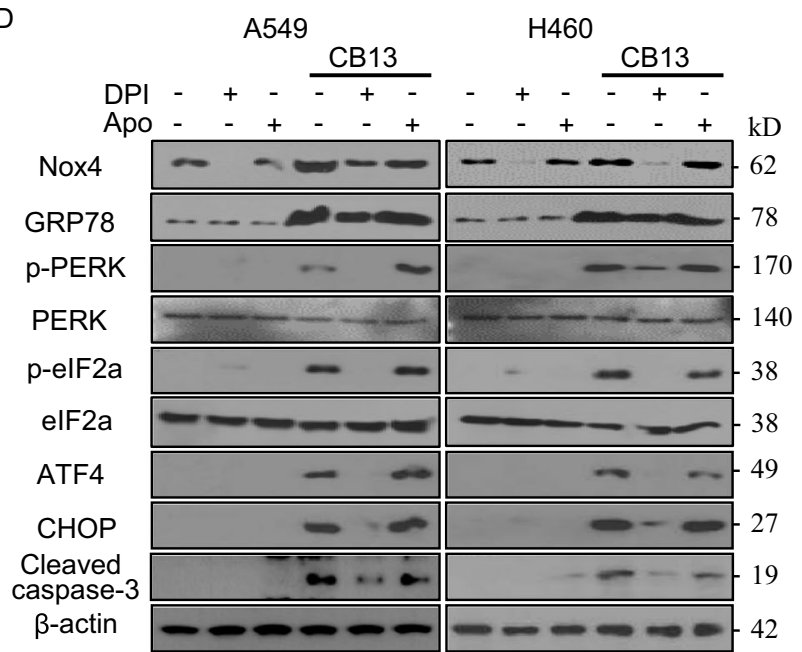

Fig. 5 DPI inhibits CB13-mediated apoptotic cell death in NSCLC cells. a FACs data indicate the change in fluorescence intensity of DCFDA dye in CB13-treated $(30 \mu \mathrm{M}, 8 \mathrm{~h})$ or Cig-treated $(10 \mu \mathrm{M}, 24 \mathrm{~h}) \mathrm{A} 549$ and H460 cells; ${ }^{*} P<0.05$. b-d A549 and H460 cells were treated with DPI (1 $\left.\mu \mathrm{M}, 24 \mathrm{~h}\right)$, Apo $(100 \mu \mathrm{M}, 24 \mathrm{~h})$, and CB13 $(30 \mu \mathrm{M}, 24 \mathrm{~h})$. Cell viability was determined using a WST-1 assay, and LDH cytotoxicity was measured using an LDH assay; ${ }^{*} P<0.05$. A Western blot analysis examining GRP78, p-PERK, $\mathrm{p}$-elF2a, ATF4, CHOP, and cleaved caspase-3 levels was performed using these samples. $\beta$-actin was used as the protein loading control.

\section{A combination of $\mathrm{CB} 13$ and radiation overcomes radio- resistance}

Radiotherapy is a common therapeutic strategy for the treatment of NSCLC even though radio-resistance frequently occurs. Exactly how radio-resistance occurs is still unclear and better mechanistic studies are necessary to discover the underlying causes ${ }^{38,39}$. To assess whether CB13 causes radio-sensitivity in radio-resistant NSCLC cells, we performed colony formation assays, cell viability assays, and Western blot analyses. Our results showed that CB13 causes a synergistic reduction in the surviving fraction levels depending on the level of radiation exposure (2, 4, or 6Gy) on NSCLC (A549 and H460) and radio-resistant NSCLC cells (A549R and H460R) when compared to control cells (Fig. 7a). Additionally, surviving fraction levels were higher in CB13-treated A549 and H460 cells when compared to CB13-treated A549R and H460R cells (Fig. 7a). In A549 and H460 cells, CB13 decreased cell viability, 2 Gy/CB13 decreased cell viability even further, and $2 \mathrm{~Gy}$, alone, had no effect (Fig. 7b). In A549R and H460R cells, CB13 decreased cell viability, 2 Gy/CB13 decreased cell viability even further, and 2 Gy, alone, had no effect (Fig. 7b). Furthermore, CB13 or 2 Gy/ CB13 causes greater cell viability in A549R and H460R cells when compared to A549 and H460 cells (Fig. 7b). To probe whether $2 \mathrm{~Gy} / \mathrm{CB} 13$ contributes to cell death via ER stress, we carried out a Western blot analysis. In A549 and H460 cells, 2 Gy of radiation caused an increase in pPERK expression, but it had no effect on the expression of CHOP or cleavage of caspase-3. CB13 treatment up- 


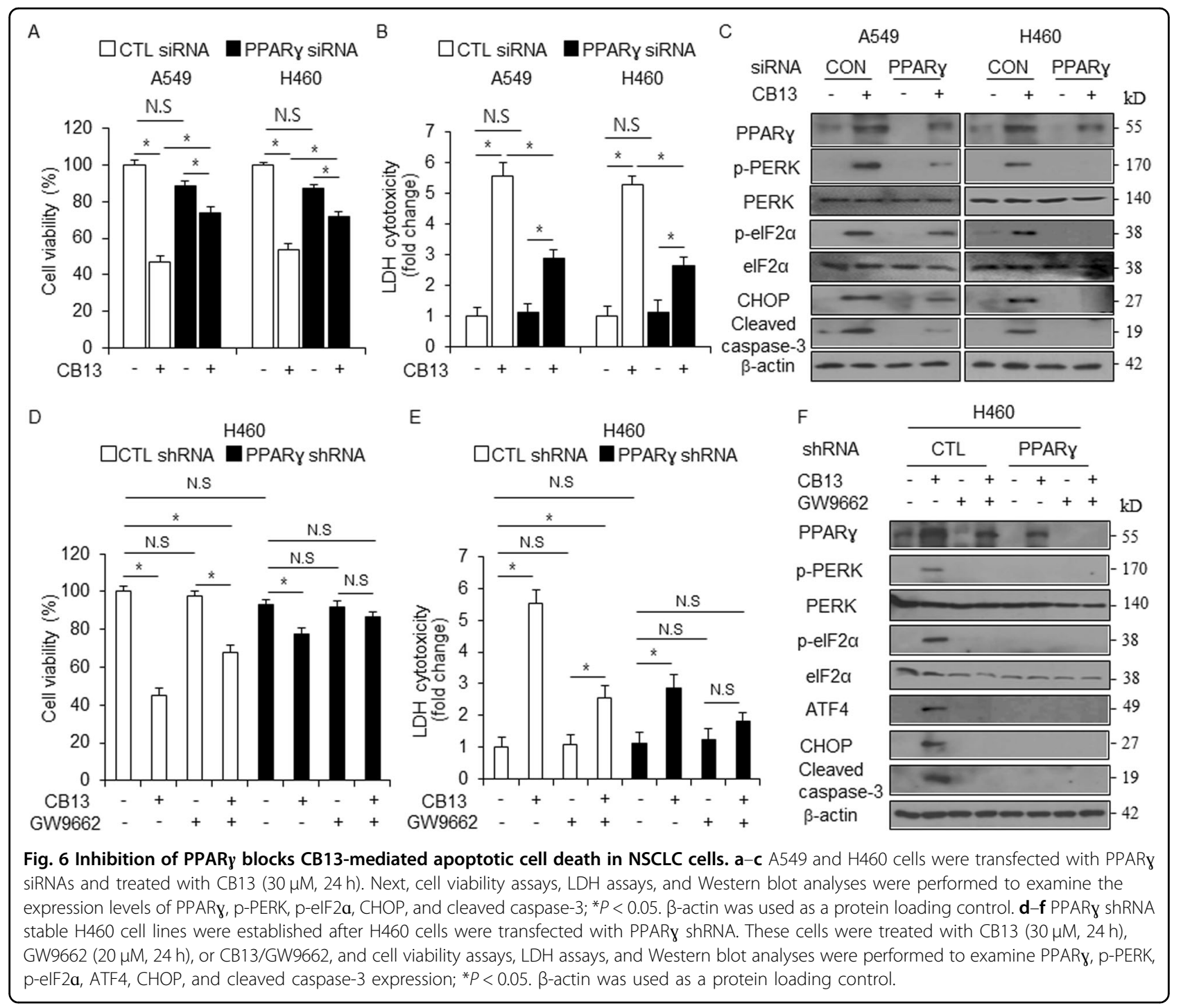

regulated the expression of p-PERK and $\mathrm{CHOP}$ and cleavage of caspase- 3 in A549 and $\mathrm{H} 460$ cells when compared to 2 Gy treatment, alone. $2 \mathrm{~Gy} / \mathrm{CB} 13$ treatment dramatically increased the expression of p-PERK and CHOP (ER stress markers) and cleavage of caspase-3 when compared to CB13 alone (Fig. 7c). In A549R and H460R cells, $2 \mathrm{~Gy}$, alone, had no effect on the expression of most ER markers, and CB13 weakly increased the expression of p-PERK and CHOP and cleavage of caspase3. Interestingly, $2 \mathrm{~Gy} / \mathrm{CB} 13$ synergistically increased the expression of p-PERK and CHOP and the cleavage of caspase- 3 in A549R and H460R cells.

\section{PPARy inhibition suppresses $2 \mathrm{~Gy} / \mathrm{CB} 13$-induced radio- sensitivity}

To further investigate whether $2 \mathrm{~Gy} / \mathrm{CB} 13$ can overcome radio-resistance, we established stable PPARy knockdown cells by transfecting PPARy shRNA in H460R cells. We treated these stable knockdown cells with CB13, $2 \mathrm{~Gy}$, or $2 \mathrm{~Gy} / \mathrm{CB} 13$ and performed cell viability assays, LDH assays, and Western blot analyses. In control (CTL) stable H460R cells, CB13 decreased cell viability and increased LDH cytotoxicity. CB13, in combination with $2 \mathrm{~Gy}$, caused even lower cell viability and higher LDH release, but $2 \mathrm{~Gy}$, alone, had no effect. However, in PPARy knockdown stable H460R cells, CB13, 2 Gy, and $2 \mathrm{~Gy} /$ CB13 had no effect, which indicates PPARy inhibition blocks 2 Gy/CB13-mediated radio-sensitivity of radioresistant cells (Fig. 8a, b). Western blot analysis showed that $2 \mathrm{~Gy}$ did not induce the expression of the indicated markers in CTL stable H460R cells. CB13 induced weak expression of PPARy, p-PERK, and CHOP and cleavage of caspase-3, but 2 Gy/CB13 caused dramatically higher expression levels of PPARy, p-PERK, and CHOP and cleavage of caspase-3 when compared to 2 Gy or CB13, alone (Fig. 8c). In PPARy knockdown H460R cells, CB13 


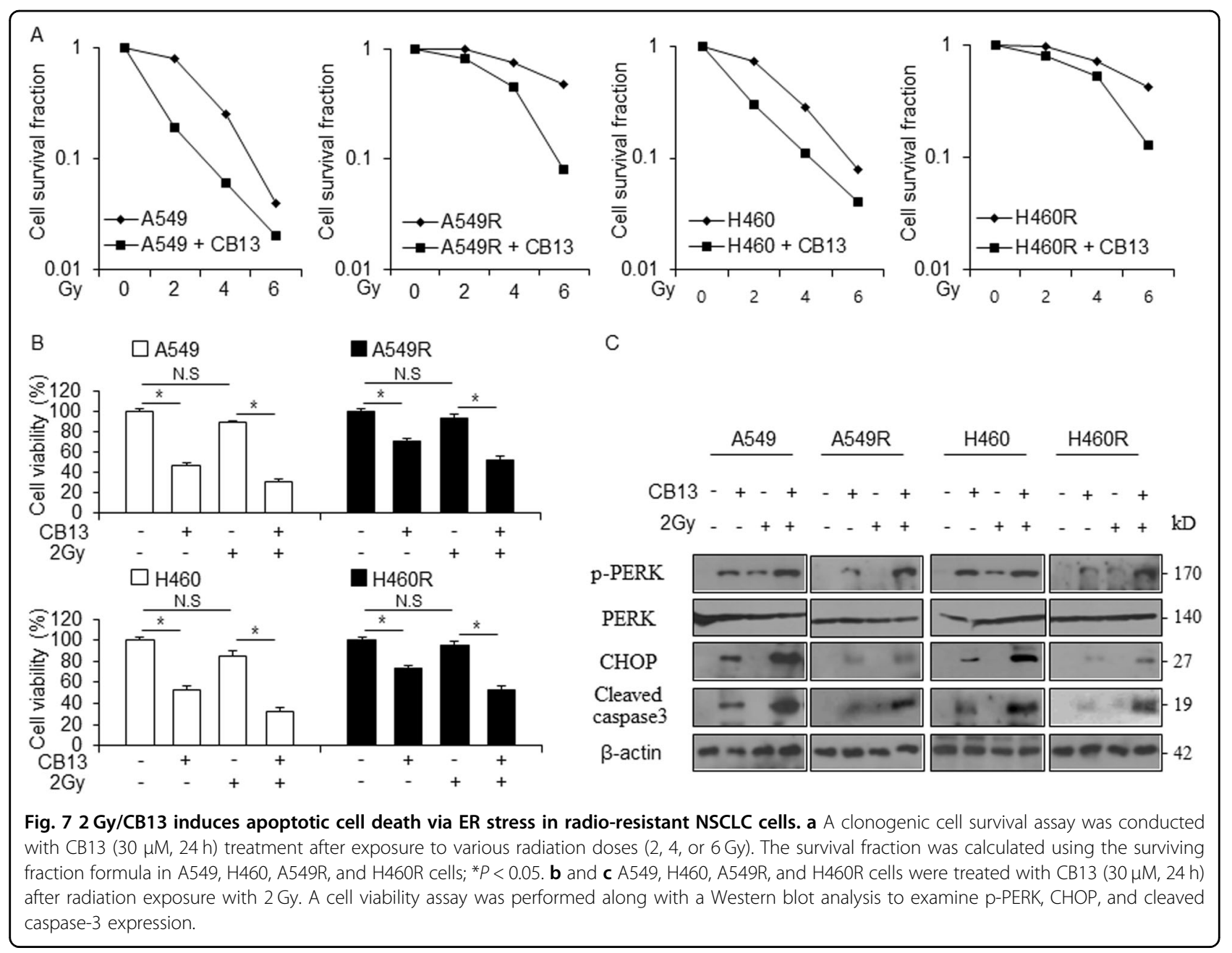

treatment caused a small increase in PPARy expression, and $2 \mathrm{~Gy}$ or $2 \mathrm{~Gy} / \mathrm{CB} 13$ showed almost no increase in PPARy expression.

\section{Discussion}

In this study, we showed that CB13, a novel PPAR- $\gamma$ agonist, causes cell death via ROS production and ER stress in human NSCLC cells. Also, DPI, a ROS inhibitor, suppresses CB13-induced cell death. CB13, in combination with radiation (2 Gy), induces cell death via ER stress in radio-resistant NSCLC cells; however, inhibition of ER stress or PPARy blocks cell death in CB13-treated radioresistant NSCLC cells. These results suggest that CB13 is a novel anti-tumor agent that overcomes radio-resistance in NSCLC.

PPARY is expressed in a variety of cancer types, including breast, colon, lung, liver, pancreas, stomach, neuroblastoma, and thyroid ${ }^{40}$. PPARy ligands such as 15D-PGJ ${ }_{2}$, TGZ, RGZ, Cig, pioglitazone, and rosiglitazone are used to treat diabetes, but they also inhibit the proliferation of cancer by influencing apoptosis pathways ${ }^{41}$.
15D-PGJ2 and Cig cause cell death via a PPARy-dependent pathway, but TZD and rosiglitazone cause cell death via both PPARy-dependent and PPARy-independent pathways, respectively ${ }^{42,43}$. Our findings suggest that CB13 exhibits powerful anti-cancer effects through PPARy expression in NSCLC cells, (similar to Cig), and knocking down PPARy inhibits CB13-induced PPARy expression and cell death. Thus, the apoptosis signaling axis through CB13-induced PPARy expression may be a potential pathway in anti-cancer therapy. PPARy ligands regulate caspase-dependent apoptosis pathways in various cancer types (e.g. lung, liver, breast, colon, and brain) ${ }^{44}$. CB13 and Cig cause cell death via caspase-9- and -3dependent pathways in NSCLC cells, respectively. Conversely, Z-VAD-FMK, a caspase inhibitor, blocks CB13induced caspase-dependent apoptosis in NSCLC cells. Taken together, CB13 treatment up-regulated apoptosisrelated markers inhibited by Z-VAD-FMK, and there is a close relationship between CB13 treatment and apoptosis.

ROS plays roles in both cell survival and cell death in various cancer types ${ }^{45}$. Increased ROS production causes 


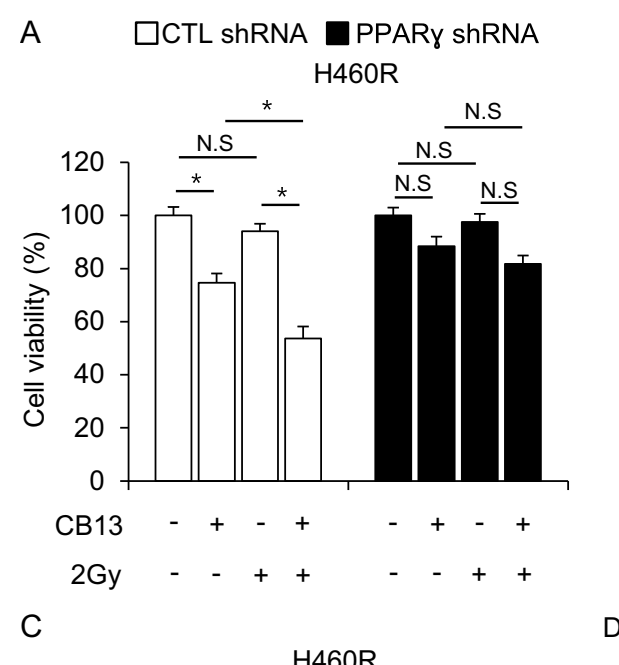

B $\square$ CTL shRNA $\underset{\text { H460R }}{\square \text { PPARY ShRNA }}$
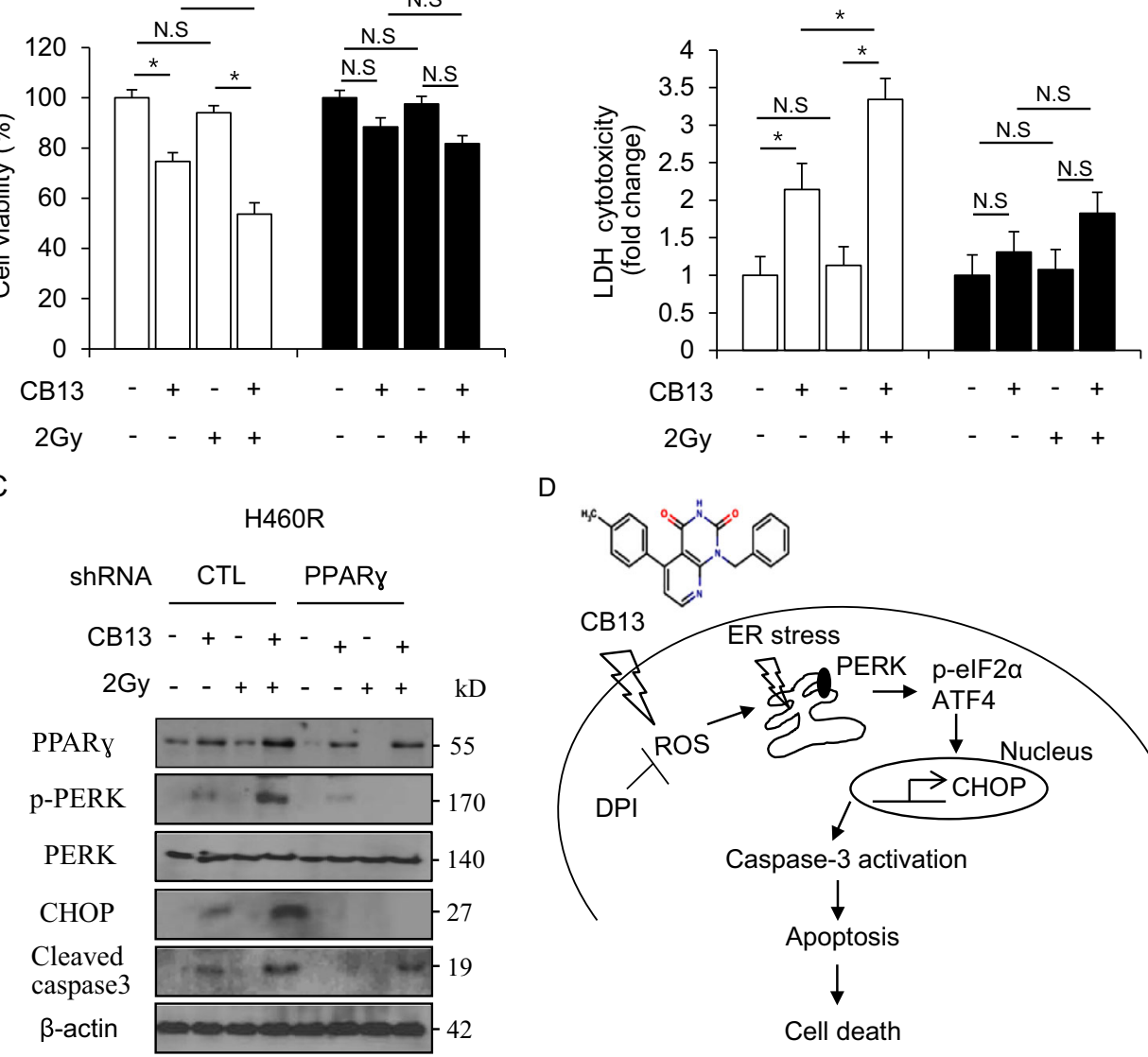

D

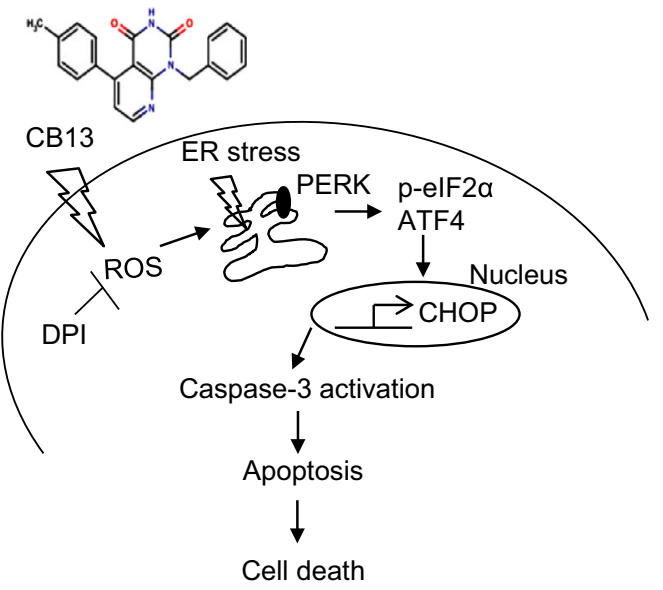

Fig. 8 Inhibition of PPARy suppresses 2 Gy/CB13-induced apoptotic cell death in radio-resistant H460R cells. a-c After H460R cells were transfected with PPARy shRNA, they established PPARy shRNA stable H460R cell lines. These cells were treated with CB13 (30 $\mu \mathrm{M}, 24 \mathrm{~h})$ after $2 \mathrm{~Gy}$ exposure, and cell viability assays, LDH assays, and Western blot analysis was performed to examine PPARy, p-PERK, CHOP, and cleaved caspase-3 expression; ${ }^{*} P<0.05$. $\beta$-actin was used as a protein loading control. $\mathbf{d}$ Schematic representation of the apoptotic cell death pathways stimulated by CB13 in NSCLC and radio-resistant NSCLC cells.

apoptosis and DNA damage in various cancers and has diverse anti-cancer effects ${ }^{46}$. $15 \mathrm{D}$-PJ2 causes apoptosis and decreases cancer cell proliferation by increasing ROS production and proline oxidase (POX, mitochondrial redox enzyme) levels in cancer cells, and the inhibition of POX blocks PPARy-induced ROS generation ${ }^{47}$. Cig also induces cell death through ROS generation in NSCLC cells, and NAC suppresses Cig-induced apoptosis ${ }^{48}$. Our data suggest that Apo does not inhibit CB13-mediated ROS production or cell death in NSCLC cells, but DPI suppresses CB13-induced ROS generation and apoptosis. These findings indicate that CB13 causes cell death via ROS production in NSCLC cells and may exist with a variety of anti-oxidant defences, such as superoxide dismutases (SOD), catalase, glutathione peroxidase, peroxiredoxins, glutathione (GSH), lipoic acid, carotenoids, and iron chelators.
ROS regulates various cellular processes (e.g. signal transduction, DNA repair, and protein folding), and excessive ROS activates pro-apoptotic signaling pathways that involve mitochondrial dysfunction, ER stress, and DNA damage ${ }^{49}$. Recent reports suggest that PPARy ligands induce ER stress and apoptosis in NSCLC cells, and CHOP, a major mediator of ER stress, is a key marker of ER stress-induced cell death ${ }^{50}$. Furthermore, ER stress activates the UPR, which is regulated by trans-membrane receptors including PERK, ATF6, and IRE1 $\alpha^{51}$. CB13 upregulates ER stress markers (e.g. p-PERK, p-eIF2 $\alpha$, ATF4, cleaved caspase- 3 , and $\mathrm{CHOP}$ ), and TG, an ER stress inducer, has a synergic effect on ER stress in CB13-treated NSCLC cells. Inhibition of PERK or CHOP blocks CB13induced ER stress and apoptosis, indicating that CB13 causes cell death via ER stress. Excessive levels of ROS generation cause cellular damage via the activation of cell 
death such as apoptosis and ER stress. Recent studies suggest that multi-vesicular body (MVB) formation and exosomes increase during ER stress, and PERK and IRE1 $\alpha$ deficiencies suppress ER stress-mediated exosome release $^{52}$. We isolated exosomes from the growth medium of CB13-treated NSCLC cells in a time-dependent manner, and the levels of exosomal marker protein CD63 were higher in CB13-treated exosomes when compared to control cells. We observed up-regulation of GRP78 and $\mathrm{CHOP}$ during these exosome experiments, and exosomes isolated from PERK knock-down cells inhibited CB13induced CD63 and CHOP levels, indicating an inhibition of ER stress. Thus, these result suggest new insight into how exosomes containing GRP78 regulate ER stress and cell death in CB13-treated tumor microenvironment.

Radio-resistance frequently manifests during tumor radiotherapy and is considered a major clinical problem ${ }^{53}$. Unfortunately, the underlying mechanism that causes radio-resistance and an effective tumor therapeutic strategy remain unclear $^{54}$. To identify whether CB13 overcomes radio-resistance, radio-resistant A549R and H460R cells were established with continuous radiation exposure. The cell survival fraction data indicate that CB13 treatment causes a lower cell survival fraction in radio-resistant NSCLC cells when compared to control cells, suggesting that $\mathrm{CB} 13$ overcomes radio-resistance. Treating A549R and H460R cells with CB13 reduced cell viability and enhanced LDH release when compared to cells treated with 2 Gy. Treating radio-resistant NSCLC cells with a combination of 2 Gy and CB13 caused a synergistic decrease in cell viability and a greater increase in LDH cytotoxicity than in cells treated with 2 Gy or $\mathrm{CB} 13$, alone. We may expect that CB13 in combination with radiation exposure used effective clinical therapy for overcoming radiation resistance problem. To investigate the molecular mechanism used by $\mathrm{CB} 13$ to overcome radio-resistance, we examined ER stress pathways. Western blot analysis indicated that $\mathrm{CB} 13$, in combination with $2 \mathrm{~Gy}$, induces ER stress and cell death by increasing the expression of p-PERK and CHOP, and the cleavage of caspase-3 in A549R and H460R cells when compared to cells treated with 2 Gy or CB13, alone. Together, CB13 and 2 Gy have a synergistic effect on ER stress and cell death in radio-resistant cells, which indicates 2 Gy/CB13 can overcome radio-resistance. In these circumstances, PPARy ligand-mediated ER stress could become an effective strategy to overcome radio-resistance. Our data suggest that $\mathrm{CB} 13$ regulates ER stress and apoptosis via activation of PPARy in NSCLC cells. We established PPARy knockdown-stable H460R cells using PPARy shRNA, and when treated with CB13, 2 Gy, or 2 Gy/CB13, they showed no decrease in cell viability; no up-regulation of PPARy, p-PERK, and CHOP expression; and no increase in caspase- 3 cleavage. Hence, it identified that
radiation/CB13 overcome radiation resistance via ER stress.

In conclusion, CB13 overcomes radio-resistance and induces cell death through PPARy activation, ROS generation, and ER stress in NSCLC and radio-resistant NSCLC cells; however, inhibition of ROS or PPARy blocks cell death in CB13-treated NSCLC and radioresistant NSCLC cells. Our findings suggest that CB13 is a novel chemotherapeutic anti-cancer agent and potential drug that can overcome radio-resistance in NSCLC cells.

\section{Materials and methods \\ Reagents}

Propidium iodide (PI), and antioxidants including apocynin (Apo, a ROS inhibitor) and diphenyleneiodonium (DPI, a Nox inhibitor) were purchased from SigmaAldrich (St. Louis, MO). Cig and the selective PPARy antagonist GW9662 were obtained from Cayman (Ann Arbor, MI). The PPARy agonist candidate, CB13, was obtained from Chembridge (USA).

\section{Cell culture}

Pre-adipose mouse cell lines (3T3-L1) and human nonsmall cell lung cancer (NSCLC) cell lines (A549 and H460) were purchased from the American Type Culture Collection (ATCC, Manassas, VA). Cells were grown in Dulbecco's modified Eagle's medium (DMEM) supplemented with $10 \%$ fetal bovine serum (FBS), $100 \mathrm{U} / \mathrm{mL}$ penicillin, and $100 \mu \mathrm{g} / \mathrm{mL}$ streptomycin (Gibco BRL Life Technologies, Gaithersburg, MD, USA) at $37{ }^{\circ} \mathrm{C}$ under $5 \%$ $\mathrm{CO}_{2}$. Stock solutions of $\mathrm{Cig}(10 \mathrm{mM})$ and $\mathrm{CB} 13(50 \mathrm{mM})$ were prepared in dimethyl sulfoxide (DMSO). Cig $(10 \mu \mathrm{M})$ and $\mathrm{CB} 13(30 \mu \mathrm{M})$ were added to the culture media in the presence or absence of antioxidants. Culture medium containing $0.2 \%$ FBS was used when cells were treated with PPARY ligands.

\section{Oil Red $O$ staining}

3T3-L1 preadipocytes were pretreated with $\mathrm{Cig}$ $(10 \mu \mathrm{M}), \mathrm{CB} 13(30 \mu \mathrm{M})$, or the PPARy antagonist GW 9662 along with differentiation inducers. 3T3-L1 cells were seeded in a six-well plate at a density of $2 \times 10^{4}$ cells per well in DMEM supplemented with 10\% FBS, $100 \mathrm{U} /$ $\mathrm{mL}$ penicillin, and $100 \mu \mathrm{g} / \mathrm{mL}$ streptomycin. After 3T3-L1 cells maintained $80 \%$ confluency for 2 days, the medium was exchanged with DMEM containing 10\% FBS, $1 \mu \mathrm{M}$ dexamethasone (Dex, Sigma-Aldrich), $0.5 \mathrm{mM}$ 3-isobutyl1-methyl-xanthine (IBMX, Sigma-Aldrich), and $5 \mu \mathrm{g} / \mathrm{mL}$ insulin (Sigma-Aldrich) for $48 \mathrm{~h}$. After differentiation, the medium was exchanged with DMEM supplemented with $10 \% \mathrm{FBS}$ and $5 \mu \mathrm{g} / \mathrm{mL}$ insulin twice every $48 \mathrm{~h}$. At day 8 , the ability of differentiated cells to accumulate intracellular lipids was assessed by Oil Red O staining. Cells were washed twice with PBS and chemically fixed with a 3.7\% 
formaldehyde solution. The fixative solution was removed by rinsing twice with PBS, and the cells were stained with an Oil Red O working solution for $30 \mathrm{~min}$ at room temperature. The stain was removed by washing three times with deionized and distilled water. Cells were then visualized by phase-contrast microscopy (Olympus, Tokyo, Japan), and images were obtained with a digital camera (Camedia C-5060, Japan). The Oil Red O stain was then eluted with isopropyl alcohol, and its absorbance was measured at $510 \mathrm{~nm}$.

\section{Cell viability}

Cell viability was determined using a WST-1 (4-[3-(4iodophenyl)-2-(4-nitrophenyl)-2H-5-tetrazolio]-1,3-benzene disulfonate) assay (Roche Applied Science, Indianapolis, IN, USA). Cell absorbance was measured at $450 \mathrm{~nm}$ using an enzyme-linked immunosorbent assay reader (SpectraMax190, Microplate Reader, Molecular Devices, CA, USA). The WST-1 assay used human NSCLC cell lines (A549 and H460) and radio-resistant NSCLC cell lines (A549R and H460R) plated in a 96-well plate overnight. The cells were treated with various concentrations of $\mathrm{CB} 13$ for various amounts of time.

\section{LDH assay}

Human NSCLC cells were seeded and grown on a 96well plate with growth medium. To determine the LDH (Thermo Scientific Pierce) activity in supernatants, an LDH assay was performed with $100 \mu$ l of the LDH reagent, and the solution was incubated for $30 \mathrm{~min}$ in a dark room. The LDH activity was determined by measuring the absorbance of the samples at 490 or $492 \mathrm{~nm}$ using an ELISA plate reader.

\section{Caspase- 3 and caspase- 9 activity assay}

A caspase- 3 and caspase- 9 activity assay (the Biovision colorimetric caspase- 3 and caspase-9 assay kit) was performed according to the manufacturer's instructions. A549 and H460 cells were treated with Cig $(30 \mu \mathrm{M} ; 24 \mathrm{~h})$ and CB13 in a dose-dependent manner $(0,10$, and $30 \mu \mathrm{M}$; $24 \mathrm{~h})$. Cell lysis buffer $(50 \mu \mathrm{l})$ was added to the cells and incubated for $10 \mathrm{~min}$ on ice. Samples were centrifuged at $10,000 \times g$ for $1 \mathrm{~min}$, and the protein concentration were quantified. Twenty (20) $\mu$ g of total cellular protein was prepared and mixed with $2 \times$ reaction buffer $(50 \mu \mathrm{l})$ and $4 \mathrm{mM}$ DEVD- $p$ NA substrate $(5 \mu \mathrm{l})$ or $4 \mathrm{mM}$ LEHD- $p$ NA substrate $(5 \mu \mathrm{l})$. After incubating for $1 \mathrm{~h}$ at $37^{\circ} \mathrm{C}$, the caspase- 3 and caspase- 9 activities were analyzed at $405 \mathrm{~nm}$ using a spectrophotometer (Molecular Devices).

\section{Colony formation assay}

NSCLC and radio-resistant NSCLC cells were trypsinized, counted, and plated onto $60-\mathrm{mm}$ dishes at a density of $1000 \mathrm{cells} / \mathrm{dish}$. They were then treated as indicated and cultured for 10-12 days to allow for colony formation. The colonies were fixed and stained with $0.5 \%$ crystal violet in $50 \%$ ethanol, and dishes containing more than 100 cells per plate were counted. The survival fraction was calculated using the following formula: surviving fraction $=$ number of colonies formed/number of cells seeded $\times$ plating efficiency of the control group.

\section{FACs}

For cell cycle analysis, NSCLC cells were fixed with 80\% cold ethanol, stained with a solution containing PI and RNase A (Sigma), and exposed to CB13 $(30 \mu \mathrm{M})$ for $24 \mathrm{~h}$. CB13-induced ROS generation during apoptosis was monitored by staining the cells with cell-permeant $2^{\prime} 7^{\prime}$ dichlorodihydrofluorescein diacetate $\left(\mathrm{CM}-\mathrm{H}_{2} \mathrm{DCFDA}\right.$, Invitrogen). For Annexin V/PI measurements, the cells were stained with the dye for $30 \mathrm{~min}$ using the Annexin V-FITC kit (Biovision, Palo Alto, CA, USA) in accordance with the manufacturer's instructions. The number of apoptotic cells was evaluated using the FACScan cytometer (Program Cell Quest, BD Biosciences).

\section{Irradiation}

Ionizing radiation exposure was performed using ${ }^{137} \mathrm{Cs}$ as the radiation source (Atomic Energy of Canada, Ltd., Mississuga, ON, Canada). For combination treatments, NSCLC and radio-resistant NSCLC cells were pre-treated with CB13 $(30 \mu \mathrm{M})$ for $2 \mathrm{~h}$, stimulated, and incubated for $24 \mathrm{~h}$ after 2 , 4, or 6 Gy exposure.

\section{Generation of radio-resistant A549 and $\mathrm{H} 460$ cell lines}

Cells were subjected to $2 \mathrm{~Gy}$ radiation daily for 3 months, taking weekends off. Throughout the irradiation process and recovery time, cells were kept at $40-70 \%$ confluency to ensure exponential growth. After completing the second week of radiation treatment, the cells were maintained in media containing $10 \%$ FBS. They were washed and re-fed daily for the first 7 days and then every third day thereafter. Radio-selected radio-resistance was verified by comparing the radio-sensitivity of the radiation-selected cells with their respective parental cell lines using a colony survival assay.

\section{Transfection}

Human NSCLC cells in a six-well plate were transfected with double-stranded siRNAs $(30 \mathrm{nmol} / \mathrm{mL})$ against PERK (Santa Cruz), CHOP (Santa Cruz), and PPARy (Santa Cruz) and shRNAs against PPARy (Santa Cruz) for $24 \mathrm{~h}$ using Lipofectamine 2000 (Invitrogen, Grand Island, $\mathrm{NY}$ ) according to the manufacturer's protocol. For the luciferase reporter assay, plasmids were transiently transfected using Lipofectamine2000. To confirm luciferase reporter assay results, the luciferase pGL3 vector $(2 \mu \mathrm{g}$, Promega) and the PPRE-luciferase pGL3 vector 
(2 $\mu \mathrm{g}$, Promega) were co-transfected with $0.2 \mathrm{~g}$ of CMV$\beta$-GAL, a eukaryotic expression vector in which the Escherichia coli $\beta$-galactosidase (Lac Z) structural gene is under the transcriptional control of the CMV promoter. Luciferase reporter activity was assessed on a luminometer with a luciferase assay system (Promega, Madison, WI) according to the manufacture's protocol. The luciferase assay data represent the mean \pm SD of three independent experiments.

\section{Western blot analyses}

Human NSCLC cells were solubilized in radioimmunoprecipitation assay (RIPA) lysis buffer (Bio-rad). The primary antibodies used were: $\beta$-actin (Santa Cruz, 1:1000); CD63 (Abcam, 1:1000); PPARy (Proteintech, 1:1000); and cleaved PARP, cleaved caspase-3, cleaved caspase-9, p-PERK (Thr980), ATF4, CHOP, and p-eIF2a (Ser51) (Cell Signaling, 1:1000). Primary antibodies were detected using a horseradish peroxidase-conjugated secondary antibody, and the membranes were visualized with Western Chemiluminescent HRP Substrate (Millipore).

\section{Measuring ROS}

NSCLC cells were exposed to CB13 $(30 \mu \mathrm{M})$ for $8 \mathrm{~h}$. ROS generation was measured after staining with 5-(and6)-carboxy-2', $7^{\prime}$-dichlorodihydrofluorescein diacetate (DCF-DA; Molecular Probes), which interacts with ROS to form a fluorescent complex. DCF fluorescence was immediately measured by FACS Calibur flow cytometry (Becton Dickinson). The data were acquired and analyzed using the Cell Quest Pro software.

\section{Exosome isolation}

Exosomes were obtained from the cell culture supernatants of A549 and H460 cells treated with DMSO and CB13 $(30 \mu \mathrm{M})$ using the total exosome isolation reagent (for cell culture media) according to the manufacturer's protocol (Thermo Fisher Scientific). Protein concentrations were measured using the BCA method (Thermo Scientific). The protein samples $(15 \mu \mathrm{g})$ were also quantified by Ponceau $\mathrm{S}$ staining. Positive exosomes were identified using the exosome marker, CD63.

\section{Statistical analysis}

Data are expressed as the mean \pm standard error (SE). Statistical analyses of the experimental data were performed using a two-sided Student's $t$-test. $P$-values $<0.05$ were deemed statistically significant.

\footnotetext{
Acknowledgements

This study was supported by a National Research Foundation of Korea (NRF) grant (No. 2017 R1D1A1B03033922) and a grant from the Korea Institute of Radiological and Medical Sciences (KIRAMS), which was funded by the Ministry of Science, ICT (MSIP) Republic of Korea (50531-2019).
}

Conflict of interest

The authors declare that they have no conflict of interest.

\section{Publisher's note}

Springer Nature remains neutral with regard to jurisdictional claims in published maps and institutional affiliations.

Supplementary Information accompanies this paper at (https://doi.org/ 10.1038/s41419-020-03065-w).

Received: 20 December 2019 Revised: 20 August 2020 Accepted: 24 August 2020

Published online: 13 October 2020

\section{References}

1. Bray, F. et al. Global cancer statistics 2018: GLOBOCAN estimates of incidence and mortality worldwide for 36 cancers in 185 countries. CA Cancer J. Clin. 68, 394-424 (2018).

2. Sher, T., Dy, G. K. \& Adjei, A. A. Small cell lung cancer. Mayo Clin. Proc. 83, 355-367 (2008).

3. Olaussen, K. A. \& Postel-Vinay, S. Predictors of chemotherapy efficacy in nonsmall-cell lung cancer: a challenging landscape. Ann. Oncol. 27, 2004-2016 (2016).

4. Yun, H. S. et al. Radiotherapy diagnostic biomarkers in radioresistant human H460 lung cancer stem-like cells. Cancer Biol. Ther. 17, 208-218 (2016).

5. West, C. M. et al. The intrinsic radiosensitivity of normal and tumour cells. Int. J. Radiat. Biol. 73, 409-413 (1998).

6. Balmukhanov, S. B., Yefimov, M. L. \& Kleinbock, T. S. Acquired radioresistance of tumour cells. Nature 216, 709-711 (1967)

7. Marie-Egyptienne, D. T., Lohse, I. \& Hill, R. P. Cancer stem cells, the epithelial to mesenchymal transition (EMT) and radioresistance: potential role of hypoxia. Cancer Lett. 341, 63-72 (2013).

8. Reka, A. K., Goswami, M. T., Krishnapuran, R., Standiford, T. J. \& Keshamouni, V. G. Molecular cross-regulation between PPAR-y and other signaling pathway: implications for lung cancer therapy. Lung Cancer 72, 154-159 (2011).

9. Schoonjans, K., Staels, B. \& Auwerx, J. Role of the peroxisome proliferatoractivated receptor (PPAR) in mediating the effects of fibrates and fatty acids on gene expression. J. Lipid Res. 37, 907-925 (1996).

10. Koeffler, H. P. Peroxisome proliferator-activated receptor $r$ and cancers. Clin. Cancer Res. 9, 1-9 (2003).

11. Zieleniak, A., Wojcik, M. \& Wozniak, L. A. Structure and physiological functions of the human peroxisome proliferator-activated receptor gamma. Arch. Immunol. Ther. Exp. 56, 331-345 (2008).

12. Tsubouchi, Y. et al. Inhibition of human lung cancer cell growth by the peroxisome proliferator-activated receptor- $\gamma$ agonist through induction of apoptosis. Biochem. Biophys. Res. Commun. 207, 400-405 (2000).

13. Vallée, A. \& Lecarpentier, Y. Crosstalk between peroxisome proliferatoractivated receptor gamma and the canonical WNT/ $\beta$-catenin pathway in chronic inflammation and oxidative stress during carcinogenesis. Front. Immunol. 9, 745 (2018).

14. Rosen, E. D. et al. PPARy is required for the differentiation of adipose tissue in vivo and in vitro. Mol. Cell 4, 611-617 (1999).

15. Kim, K. Y., Ahn, J. H. \& Cheon, H. G. Apoptosis action of peroxisome proliferator-activated receptor- $\gamma$ activation in human non-small-cell lung cancer is mediated via proline oxidase-induced reactive oxygen species formation. Mol. Pharmacol. 72, 674-685 (2007).

16. Kim, S., Lee, J. J. \& Heo, D. S. PPARY ligands induce growth inhibition and apoptosis through p63 and p73 in human ovarian cancer cells. Biochem. Biophys. Res. Commun. 406, 389-395 (2011).

17. Eibl, G., Went, M. N., Reber, H. A. \& Hines, O. J. Peroxisome proliferator-activated receptor $\mathrm{y}$ induces pancreatic cancer cell apoptosis. Biochem. Biophys. Res. Commun. 287, 522-529 (2001).

18. David, B. B. \& Timothy, H. Endothelial cell apoptosis induced by the peroxisome proliferator-activated receptor (PPAR) ligand 15-deoxy-412,14-prostaglandin J2. J. Biol. Chem. 274, 17042-17048 (1999).

19. Satoh, T. et al. Activation of peroxisome proliferator-activated receptor-y stimulates the arrest and DNA-damage inducible 153 gene in non-small cell lung carcinoma cells. Oncogene 21, 2171-2180 (2002). 
20. Kitamura, S. et al. Peroxisome proliferator-activated receptor $r$ induces growth arrest and differentiation markers of human colon cancer cells. J. Cancer Res. 90, 75-80 (1999).

21. Han, S. \& Roman, J. Rosiglitazone suppresses human lung carcinoma cell growth through PPAR gamma-dependent and PPAR gamma-independent signal pathway. Mol. Cancer Ther. 5, 430-437 (2006).

22. Heaney, A. P., Fernando, M. \& Melmed, S. PPAR-gamma receptor ligands: novel therapy for pituitary adenomas. J. Clin. Investig. 9, 1381-1388 (2003).

23. Lin, M. S., Chen, W. C., Bai, X. \& Wang, Y. D. Activation of peroxisome proliferator-activated receptor gamma inhibits cell growth via apoptosis and arrest of the cell cycle in human colorectal cancer. J. Dig. Dis. 8, 82-88 (2007).

24. Yin, F. et al. Signaling pathways involved in induction of GADD45 gene expression and apoptosis by troglitazone in human MCF-7 breast carcinoma cells. Oncogene 23, 4614-4623 (2004).

25. Oyadomari, S., Araki, E. \& Mori, M. Endoplasmic reticulum stress-mediated apoptosis in pancreatic $\beta$-cells. Apoptosis 7, 335-345 (2002).

26. Weber, S. M., Chambers, K. T., Bensch, K. G., Scarim, A. L. \& Corbett, J. A. PPAR gamma ligands induce ER stress in pancreatic beta-cells: ER stress activation results in attenuation of cytokine signaling. Am. J. Physiol. Endocrinol. Metab. 297, E1171-E1177 (2004).

27. Zang, C. et al. Induction of endoplasmic reticulum stress response by TZD18, a novel dual ligand for peroxisome proliferator-activated receptor alpha/ gamma, in human breast cancer cells. Mol. Cancer Ther. 8, 2296-2307 (2009).

28. Colin-Cassin, C. et al. PPAR gamma-inactive $\triangle 2$-troglitazone independently triggers ER stress and apoptosis in breast cancer cells. Mol. Carcinog. 54, 393-404 (2015)

29. Gardner, O. S., Shiau, C. W., Chen, C. S. \& Graves, L. M. Peroxisome proliferatoractivated reseptor gamma-independent activation of p38 MAPK by thiazolidiones involves calcium/calmodulin-dependent protein kinase II and protein kinase R: correlation with endoplasmic reticulum wtress. J. Biol. Chem. $\mathbf{2 8 0}$ 10109-10118 (2005).

30. Kim, B. M., Maeng, K., Lee, K. H. \& Hong, S. H. Combined treatment with the Cox-2 inhibitor niflumic acid and PPARy ligand ciglitazone induces ER stress/ caspase-8-mediated apoptosis in human lung cancer cells. Cancer Lett. 300, 134-144 (2011)

31. Seervi, M., Rani, A., Sharma, A. K. \& Santhosh Kumar, T. R. ROS mediated ER stress induces Bax-Bak dependent and independent apoptosis in response to Thioridazine. Biomed. Pharmacother. 106, 200-209 (2018).

32. Hosoi, T., Nakashima, M. \& Ozawa, K. Incorporation of the endoplasmic reticulum stress-induced spliced form of XBP1 mRNA in the exosomes. Front Physiol. 9, 1357 (2018).

33. Nedergaard, J., Petrovic, N., Lindgren, E. M., Jacobsson, A. \& Cannon, B. PPARgamma in the control of brown adipocyte differentiation. Biochim. Biophys. Acta 1740, 293-304 (2005).

34. Szegezdi, E., Logue, S. E., Gorman, A. M. \& Samali, A. Mediators of endoplasmic reticulum stress-induced apoptosis. EMBO Rep. 7, 880-885 (2006).

35. Yoboue, E. D., Sitia, R. \& Simmen, T. Redox crosstalk at endoplasmic reticulum (ER) membrane contact sites (MCS) uses toxic waste to deliver messages. Cell Death Dis. 9, 331 (2018).

36. Banerjee, A., Banerjee, V., Czinn, S. \& Blanchard, T. Increased reactive oxygen species levels cause ER stress and cytotoxicity in andrographolide treated colon cancer cells. Oncotarget 8, 26142-26153 (2017).
37. Kim, K. Y., Ahn, J. H. \& Cheon, H. G. Apoptotic action of peroxisome proliferator-activated receptor-gamma activation in human non small-cell lung cancer is mediated via proline oxidase-induced reactive oxygen species formation. Mol. Pharm. 72, 674-685 (2007).

38. Salama, J. K. \& Vokes, E. E. New radiotherapy and chemoradiotherapy approaches for non-small-cell lung cancer. J. Clin. Oncol. 31, 1029-1038 (2013).

39. Morgan, M. A. \& Lawrence, T. S. Molecular pathways: overcoming radiation resistance by targeting DNA damage response pathways. Clin. Cancer Res. 21, 2898-2904 (2015).

40. Grommes, C., Landreth, G. E. \& Heneka, M. T. Antineoplastic effects of peroxisome proliferator-activated receptor gamma agonists. Lancet Oncol. $\mathbf{5}$ 419-429 (2004)

41. Giaginis, C., Margeli, A. \& Theocharis, S. Peroxisome proliferator-activated receptor-gamma ligands as investigational modulators of angiogenesis. Expert Opin. Investig. Drugs 16, 1561-1572 (2007).

42. Girnun, G. D. et al. Synergy between PPARgamma ligands and platinum-based drugs in cancer. Cancer Cell 11, 395-406 (2007).

43. Vella, V. et al. PPAR- $\gamma$ agonists as antineoplastic agents in cancers with dysregulated IGF axis. Front. Endocrinol. 8, 31 (2017).

44. Elrod, H. A. \& Sun, S. Y. PPARgamma and apoptosis in cancer. PPAR Res. 2008 704165 (2008).

45. Liou, G. Y. \& Storz, P. Reactive oxygen species in cancer. Free Radic. Res. 44 479-496 (2010).

46. Chen, $\mathrm{H}$. et al. Advanced glycation end products promote ChREBP expression and cell proliferation in liver cancer cells by increasing reactive oxygen species. Medicine 96, e7456 (2017).

47. Kononczuk, J. et al. Proline oxidase (POX) as a target for cancer therapy. Curr. Drug Targets 16, 1464-9 (2015)

48. Han, E. J., Im, C. N., Park, S. H., Moon, E. Y. \& Hong, S. H. Combined treatment with peroxisome proliferator-activated receptor (PPAR) gamma ligands and gamma radiation induces apoptosis by PPARY-independent up-regulation of reactive oxygen species-induced deoxyribonucleic acid damage signals in non-small cell lung cancer cells. Int. J. Radiat. Oncol. Biol. Phys. 85, e239-e248 (2013).

49. Moloney, J. N. \& Cotter, T. G. ROS signalling in the biology of cancer. Semin. Cell Dev. Biol. 80, 50-64 (2018).

50. Gardner, O. S., Shiau, C. W., Chen, C. S. \& Graves, L. M. Peroxisome proliferatoractivated receptor gamma-independent activation of p38 MAPK by thiazolidinediones involves calcium/calmodulin-dependent protein kinase ॥ and protein kinase R: correlation with endoplasmic reticulum stress. J. Biol. Chem. 280, 10109-10118 (2005).

51. Ron, D. \& Walter, P. Signal integration in the endoplasmic reticulum unfolded protein response. Nat. Rev. Mol. Cell Biol. 8, 519-529 (2007).

52. Kanemoto, S. et al. Multivesicular body formation enhancement and exosome release during endoplasmic reticulum stress. Biochem. Biophys. Res. Commun. 480, 166-172 (2016).

53. Langlands, F. E., Horgan, K., Dodwell, D. D. \& Smith, L. Breast cancer subtypes: response to radiotherapy and potential radiosensitisation. Br. J. Radiol. 86 20120601 (2013).

54. Li, Q. et al. GADD45a sensitizes cervical cancer cells to radiotherapy via increasing cytoplasmic APE1 level. Cell Death Dis. 9, 524 (2018). 